\title{
Traumatic herniation into the pericardial sac
}

\author{
Patrick W. Davis* \\ F.R.C.S.
}

Hammersmith Hospital

TRAUMATIC rupture of the diaphragm may be associated with herniation into the chest of abdominal viscera. The nature of the injury may be direct (penetrating), or indirect (blunt or crush trauma). Rupture occurs more commonly on the left side: the right side is said to be protected by the liver. This report describes a case of a pure intrapericardial hernia of traumatic origin.

\section{Case report}

S.P. a 17-year-old Jamaican boy was knocked off his bicycle and run over by a lorry 25 July 1967.

On admission. Preliminary examination showed that he had a fractured right clavicle, fractured pelvis and injuries to the chest wall anteriorly. Surgical emphysema was palpated over the front of his chest and an immediate chest X-ray showed evidence of pulmonary contusion. About $4 \mathrm{hr}$ later another chest X-ray (Fig. 1) was taken because of increasing dyspnoea. This showed a pneumothorax on the left side and a gas shadow above the diaphragm.

The next day further views of the chest (Figs. 2 and 3) and a gastrografin swallow were performed. The impression gained was that the bowel, probably colon, was situated in the anterior mediastinum, possibly in the pericardium. On this day the patient complained of increasing upper abdominal pain, and an electrocardiogram showed a sinus tachycardia of $140 / \mathrm{min}$. Laparotomy was performed through a midline epigastric incision and a dilated loop of transverse colon was found lying in front of and above the liver. This was withdrawn easily and revealed a large transverse tear in the central tendon of the diaphragm leading directly into the pericardial cavity. The tear was between 4 and 5 in. long and the margins, which were ragged, were stretched apart. There was no hernial sac. Access from below was inadequate to allow a satisfactory repair so a left thoracotomy was performed through the fifth intercostal space and the peri-

\footnotetext{
*Present address: Llandough Hospital, Cardiff.
}

cardial sac was opened. With retraction of the lower border of the heart this gave good exposure of the margins of the defect (Fig. 4). Repair was performed with horizontal mattress sutures of No. 1 Ethicon. Apart from a pelvic haematoma no other abnormality was found within the abdomen. The patient made a good recovery.

\section{Discussion}

Pilcher (1965) points out that congenital or acquired herniae may occur into the pericardium. More specifically Guthrie (1855) recorded the case of a soldier who died some months after receiving a penetrating wound of the chest at the battle of Waterloo. Autopsy revealed a hole in the central tendon of the diaphragm and there were signs of pericarditis. Guthrie stated if this man had lived long enough he might have furnished evidence of hernia of the stomach or of intestine into the pericardium'. In 1921 Bryan in a Hunterian lecture on injuries of the diaphragm, based mainly on his experiences in World War I, discussed the morbid anatomy of diaphragmatic herniae and noted that 'very rarely hernia through the central tendon into the pericardium has happened'. O'Brien (1939) described a pericardio-peritoneal communication found in the course of anatomical dissection. He surveyed the literature and found that pericardioperitoneal communications had been described in five instances in man, four in the dog and one in the ass. All were considered congenital except two occurring in adult males: these were listed as 'possibly traumatic'. No satisfactory explanation of the primary embryological aetiology of these defects was offered.

A review of American literature dealing with large numbers of traumatic diaphragmatic herniae does not include a description of herniation of abdominal viscera into the pericardial sac (Harrington, 1948, 1951 ; Hill, 1964 ; Noon, Beall \& De Bakey, 1966 ; Waldhausen et al., 1966).

Similarly the British literature does not describe such an occurrence (Marsden, 1947; Evans 


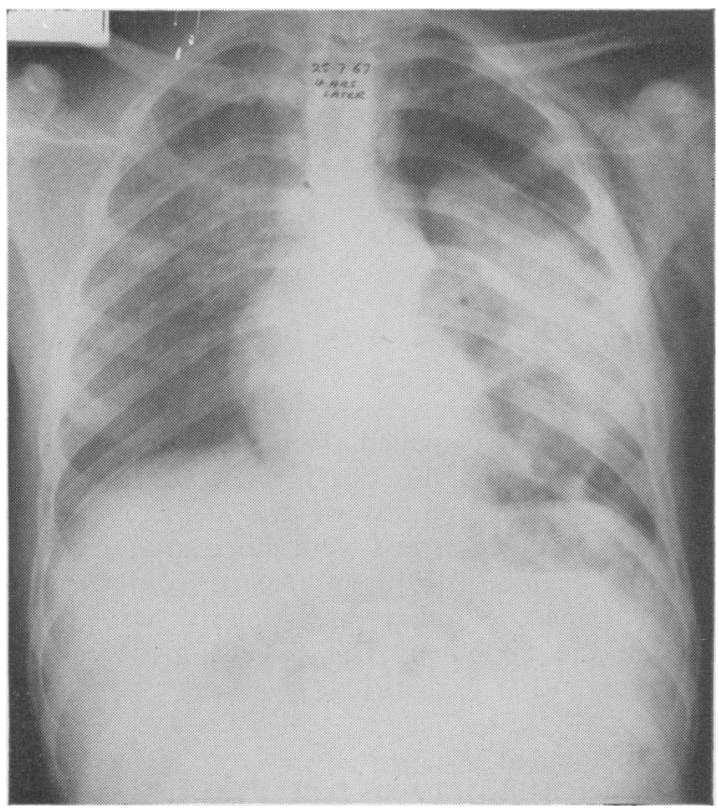

FIG. 1. Chest X-ray (erect) $4 \mathrm{hr}$ later. Note subcutaneous emphysema, the large left pneumothorax and the gas shadow above the left cupola.

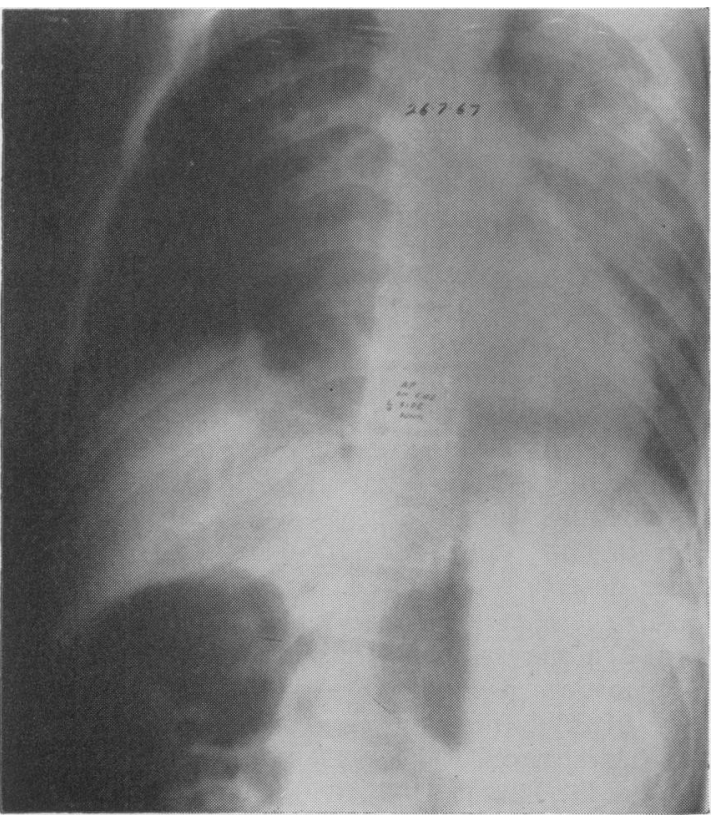

Fig. 2. Chest X-ray, AP view in left lateral decubitus. The gas is seen to move across the midline.

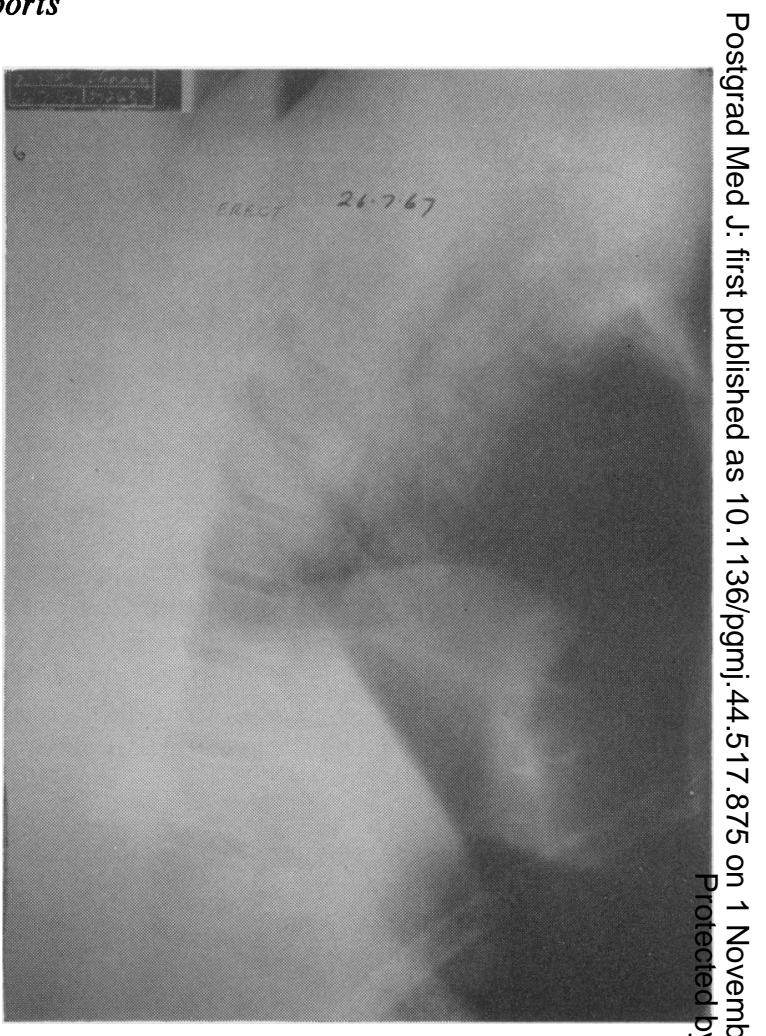

Fig. 3. Chest X-ray (erect, right lateral). A gas-filled viscus probably colon is seen lying in the anterior $O$ mediastinum.

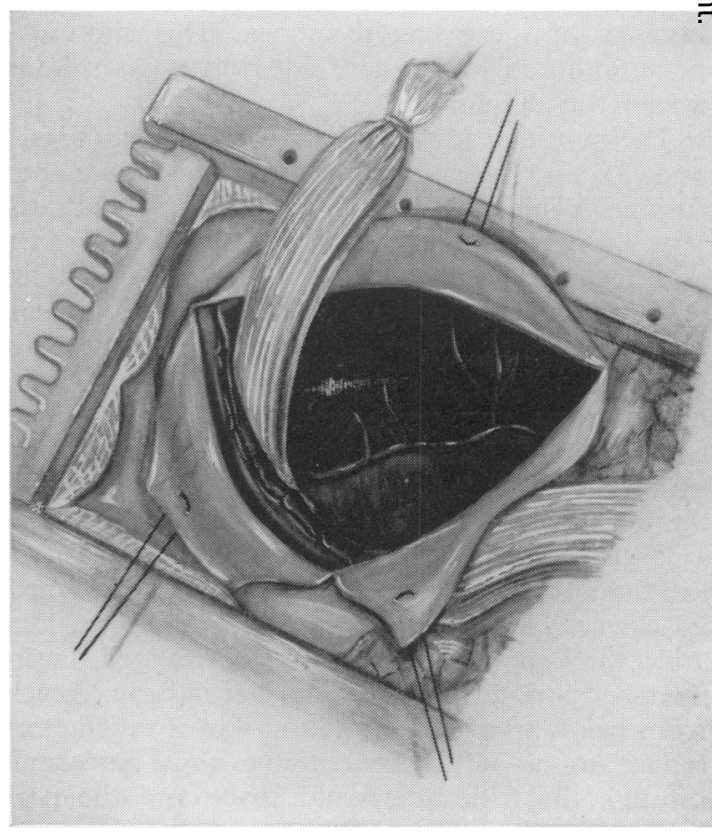

Fig. 4. Left thoracotomy: view of ruptured central tendon of diaphragm after opening pericardium. 
\& Simpson, 1950 ; Probert \& Harvard, 1961). Robb (1963) reviewed five cases of traumatic diaphragmatic hernia involving the pericardium; of these only two were confined to the pericardium. The case he added was a purely intrapericardial hernia, as was that described by Herman \& Goldstein (1965) and Nelson (1966).

All six cases, which include the subject of this report, have been related to blunt trauma; five were males, and three of these were negroes. The contents of the pericardial sac have been reported as stomach, omentum, colon and left lobe of the liver. The disposition of the tear has been reported as oblique anteroposterior in three cases and transverse in two.

\section{Diagnosis}

It is well recognized that traumatic diaphragmatic hernia may be obvious immediately or become evident later, perhaps as a result of rather bizarre alimentary symptoms. Lastly it may remain silent and undetected for a number of years and manifest itself by sudden obstruction or strangulation (Carter, Giuseffi \& Felson, 1951). Nelson's case (1966) was diagnosed some months following a road accident. Thoracotomy revealed no paraoesophageal or intrathoracic hernia though this had been outlined by plain radiography and barium studies prior to operation. Further films taken after the negative exploration showed persistence of the hernia and at a second operation stomach was found in the pericardial sac.

The diagnosis might be suspected in cases of multiple injuries which are becoming more common. In 1965,1510 patients died with 'internal injury of the chest, abdomen and pelvis', showing an increase on the preceding year when 1442 patients died from the same injuries (Registrar General 1965). In the case described here, the possibility of herniation of a viscus into the pericardial sac might have been raised on account of breathlessness, upper abdominal pain and sinus tachycardia. The diagnosis was suggested on plain $X$-ray examination in the erect position, and the decubitus film in the 'left side down' position was particularly helpful in defining the limits of the structures involved (Fig. 2). The gastrografin swallow was not helpful in this case. Barium meal with follow through and barium enema examination may be of assistance and the use of pneumoperitoneum has been recommended though Pilcher (1965) warns against the possibility of producing cardiac tamponade.

\section{Management}

The fact that $90 \%$ of strangulated diaphrag- matic herniae are traumatic in origin and most of these occur within 3 years of injury is good reason for early surgical treatment (Carter et al., 1951). Because rupture of the diaphragm is associated often with other injuries especially of the abdominal organs, an initial approach through the abdomen is advisable. This case was notable for the absence of injury to any of the abdominal viscera.

Repair of the diaphragm is performed most easily from above, and as in this case, through the pericardium. Non-absorbable suture material, placed in one or two layers, is used to obliterate the defect. Rarely small defects may heal spontaneously (Greig, 1919), but since these are more likely to be associated with obstruction or strangulation it would be foolhardy to wait for this to happen. If there is difficulty in apposing the margins of the defect, skin, fascia or man-made fibre may be used to bridge the gap, or its margins may be sutured to the liver (Sandford \& Stafford, 1956; Waldhaussen et al., 1966). Other suggestions have included the use of a pedicled pericardial flap (Desforges et al., 1957). Owing to the site of the tear in this case the question of 'splinting' the diaphragm by phrenic nerve crush or use of a ventilator did not arise.

\section{Mechanism}

Since Ambroise Paré (1579) first described traumatic rupture of the diaphragm no satisfactory explanation has been found to account for the forces involved, their manner of transmission to the diaphragm and the consequent location and direction of any tear. If the term traumatic rupture is taken to include iatrogenic causes, then incision and repair of the diaphragm for the purpose of surgical access, and subphrenic abscess may be borne in mind. A medical history which includes these events may help to explain unusual alimentary symptoms at a later date in the life of the patient. With regard to accidental trauma, it is tempting to consider rupture of the diaphragm as a local event analogous to the tearing of muscle fibres that will occur under conditions of stress in the rectus abdominis, the biceps and quadriceps femoris and the musculo-tendinous region of the calf muscles. As a result of sudden and intense contraction the diaphragm might tear; the intrinsic forces involved, asymmetrically distributed and possibly modified by external factors will account for the location and disposition of a tear. In the case presented, there was no contusion of the herniated colon: the $\mathrm{X}$-rays demonstrate that it travelled through the diaphragm some $4 \mathrm{hr}$ after the accident. This suggests that the tear in the 
diaphragm might have been the result of isolated local stress rather than the consequence of much raised intra-abdominal pressure.

\section{Acknowledgments}

The patient was admitted under the care of $\mathbf{M r} \mathbf{R}$. $\mathbf{H}$. Franklin to whom I am grateful for advice in management and for permission to publish this case. Dr F. Doyle and Dr J. Taubman were responsible for the radiology and $\mathbf{M r}$ Bracknell reproduced the X-rays for publication. Miss S. Barker of the Department of Medical Illustration provided Fig. 4.

\section{References}

BryaN, C.W.G. (1921) Injuries of the diaphragm. Brit. J. Surg. 9, 117.

Carter, B.N., Giuseffi, J. \& Felson, B. (1951) Traumatic diaphragmatic hernia. Amer. J. Roentgenol. 65, 56.

Desforges, G., Streider, J.W. LyNCH, J.P. \& MAdOfF, I.M. (1957) Traumatic rupture of the diaphragm. J. Thorac. Surg. 34, 779.

Evans, C.J. \& Simpson, J.A. (1950) Fify-seven cases of diaphragmatic hernia and eventuation. Thorax, 5, 343.

GrEIG, D.M. (1919) A case of diaphragmatic hernia following a gunshot wound. Edinb. med. J. 22, 357.

GUTHRIE, G.J. (1855) Commentaries on the Surgery of the War, etc., 6th edn, p. 513. Henry Renshaw, London.

HarRington, S.W. (1948) Various types of diaphragmatic hernia treated surgically. Surg. Gynec. Obstet. 86, 735.
Harrington, S.W. (1951) Clinical manifestations of hiatus hernia. Rev. Gastroent. 18, 243.

Herman, P.G. \& Goldstein, J.E. (1965) Traumatic intrapericardial diaphragmatic hernia. Brit. J. Radiol. 38, 631.

Hill, G.C. (1964) Some unusual cases of traumatic diaphragmatic hernia. J. nat. med. Ass. (N.Y.), 56, 401.

MARSDEN, C.M. (1947) Traumatic diaphragmatic hernia. J. roy. Army med. Corps. 89, 71.

Nelson, J.F. (1966) The roentgenologic evaluation of abdominal trauma. Rad. Clin. N. Amer. 4, 429.

Noon, G.P., Beall, A.C. \& De BAKey, M.E. (1966) Surgical management of traumatic rupture of the diaphragm. J. Trauma, 6, 344.

O'BrIEN, H.D. (1939) Pericardio-peritoneal communication: description of a rare type of diaphragmatic hernia. J. Anat. (Lond.), 74, 131.

PILCher, R.S. (1965) Thorax. Clinical Surgery (Ed. by A.L. d'Abreu, C. Robb and R. Smith), Vol. 5, p. 385. Butterworths, London.

Probert, W.R. \& Harvard, C. (1961) Traumatic diaphragmatic hernia. Thorax, 16, 99.

Registrar General (1965) Statistical Review, Part 1, Tables, Medical, pp. 175 and 176. H.M.S.O., London.

RoвB, D. (1963) Traumatic diaphragmatic hernia into the pericardium. Brit. J. Surg. 50, 664.

SANDFORD, M.C. \& STAFFoRd, E.S. (1956) Diaphragmatic hernia caused by trauma; diagnosis and treatment. Postgrad. Med. 19, 60.

Waldhausen, J.A., Kilman, J.W., Helman, C.H. \& BATTERSBY, J.S. (1966) Diagnosis and treatment of trau= matic injuries of the diaphragm. J. Trauma, 6, 332. 